\title{
Mapeamento do uso e ocupação da terra na bacia hidrográfica do rio São Domingos, RJ
}

\author{
Elaine Cristina Cardoso Fidalgo ${ }^{1}$ \\ Marcelo Bueno de Abreu ${ }^{2}$ \\ ${ }^{1}$ Empresa Brasileira de Pesquisa Agropecuária- Embrapa Solos \\ Rua Jardim Botânico, 1024 - 22460-000 - Rio de Janeiro- RJ, Brasil \\ efidalgo@cnps.embrapa.br \\ ${ }^{2}$ Universidade Federal do Rio de Janeiro- UFRJ- Instituto de Geociências \\ Avenida Brigadeiro Tromposvisky, s.n.- Rio de Janeiro- RJ, Brasil \\ buenodeabreu@yahoo.com.br
}

\begin{abstract}
The São Domingos River watershed, part of the Paraíba do Sul River watershed, has insufficient water supply during periods of low rainfall, a result of the disorderly process of land occupation. This study aimed to survey land use and land cover in the São Domingos River watershed. The main classes of land use and land cover was mapped, in addition the main cultivated areas were georeferenced for the summer and winter in the agricultural year 2004/2005, and the areas of permanent preservation (APP) were bounded. Pasture predominates in the watershed, it covers $88.30 \%$ of its area, and Natural Vegetation covers $9.24 \%$ of the watershed area. The results showed the lack of protection of most of the APP which lost the most of its forest cover and is partly occupied by intensive agricultural.
\end{abstract}

Palavras-chave: land use/land cover, remote sensing, protected areas, uso e cobertura da terra, sensoriamento remoto, áreas de preservação permanente.

\section{Introdução}

O presente estudo está inserido no projeto PRODETAB-Aquíferos, coordenado pela Embrapa Solos, que visa desenvolver um modelo preditivo da oferta hídrica em uma bacia hidrográfica e que inclui estudos para a elaboração do diagnóstico ambiental, destacando a vulnerabilidade do ambiente às intervenções antrópicas, e o monitoramento da dinâmica do sistema hídrico sob diferentes práticas de manejo das terras.

O uso e manejo inadequados das terras e a falta de ações conservacionistas implicam em perdas significativas de solo, matéria orgânica, nutrientes, biodiversidade e, em especial, de água, prejudicando o equilíbrio dos sistemas hídricos em bacias hidrográficas. O levantamento do uso e cobertura da terra como parte de um diagnóstico ambiental é a primeira etapa para o planejamento conservacionista como estratégia para a reversão desse quadro.

O presente trabalho foi desenvolvido com o objetivo geral de realizar o levantamento do uso e cobertura da terra na bacia hidrográfica do rio São Domingos, RJ. Complementarmente, como objetivos específicos têm-se o mapeamento das principais classes de uso e cobertura da terra na escala 1:50.000; o levantamento das principais áreas cultivadas no período de verão e inverno no ano agrícola 2004/2005; e a delimitação das áreas de preservação permanente e análise de sua cobertura atual.

\section{Material e Métodos}

O presente trabalho foi realizado na bacia hidrográfica do rio São Domingos (afluente do rio Muriaé, complexo hidrográfico do rio Paraíba do Sul) na região Noroeste do estado do Rio de Janeiro, abrangendo parte dos municípios de São José de Ubá e Itaperuna e totalizando 28000 ha (Figura 1). 


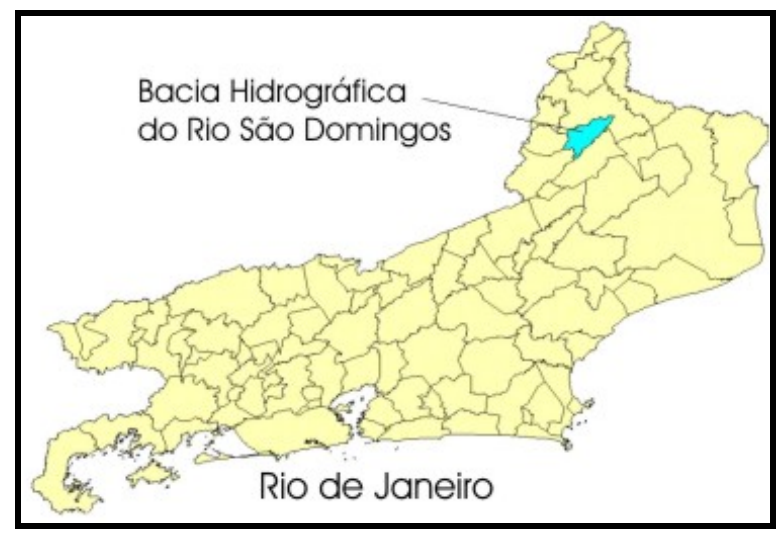

Figura 1. Localização da bacia hidrográfica do rio São Domingos no estado do Rio de Janeiro.

A região da bacia hidrográfica do rio São Domingos apresenta insuficiência de oferta hídrica nos períodos de baixa precipitação, resultado do processo desordenado de ocupação das terras, caracterizado pela retirada da cobertura vegetal original e sua substituição por sucessivos ciclos de monocultivos, os quais desencadearam processos erosivos na região e deram origem a mudanças significativas da oferta hídrica (Xavier et al., 2000; Martorano et al., 2003; Gonçalves et al., 2006; Lima, 2009). Atualmente, a cobertura vegetal encontra-se bastante reduzida, sendo a maior parte das terras ocupadas por pastagens. A principal atividade agrícola é a cultura do tomate, que ocupa pequenas parcelas de área nos meses de março a outubro.

O mapeamento do uso e cobertura da terra na área de estudo foi realizado utilizando-se imagens das bandas 1, 2 e 3N (VNIR) e 4 a 9 (SWIR) do sensor ASTER de 21/02/2002. A metodologia empregada é descrita em Fidalgo e Abreu (2004), e envolveu as seguintes etapas: a) análise de principais componentes, b) seleção das três primeiras componentes para segmentação por crescimento de regiões, c) classificação de regiões baseada na distância de Battacharya, e d) edição matricial por um fotointérprete visando a correção dos erros de classificação conforme dados levantados em campo.

Devido à pequena extensão das lavouras na área de estudo, foi necessário o levantamento em campo para localizar e identificar os principais cultivos. Os levantamentos foram realizados durante o ano agrícola 2004/2005, de forma a identificar as culturas de verão e inverno na região. O trabalho em campo envolveu o percurso em toda a área de estudo, a identificação do local de cultivo através de coleta de coordenadas do local utilizando GPS (Global Position System) e a coleta de informações junto aos produtores com a aplicação de questionários. As informações coletadas referem-se à cultura agrícola, área cultivada, data de semeadura ou plantio, e informações complementares referentes às práticas de manejo adotadas.

As áreas de preservação permanente (APPs) foram delimitadas seguindo o que estabelece o Art. $2^{0}$ do Código Florestal (Lei no 4771 de 15 de setembro de 1965, alterada pela Lei 7803 de 1989) e a Resolução CONAMA 303 de 2002. Com base nesses critérios, delimitou-se como APP: uma faixa de 30 metros ao longo de todos os cursos d'água da bacia e de 200 metros ao longo do rio Muriaé, um círculo de raio igual a 50 metros ao redor das nascentes dos cursos d'água, todas as áreas com declividade acima de $45^{\circ}$ e o terço superior de morros e montanhas. A delimitação foi realizada considerando os elementos planialtimétricos em escala 1:50 000 (IBGE, 1968 e 1976).

A situação atual das áreas de preservação permanente foi analisada integrando-se o mapeamento das APPs ao mapeamento do uso e cobertura das terras da bacia. 


\section{Resultados e Discussão}

O mapa de uso e cobertura da terra da bacia hidrográfica do rio São Domingos, elaborado originalmente em escala 1:50 000, é representado na Figura 2.
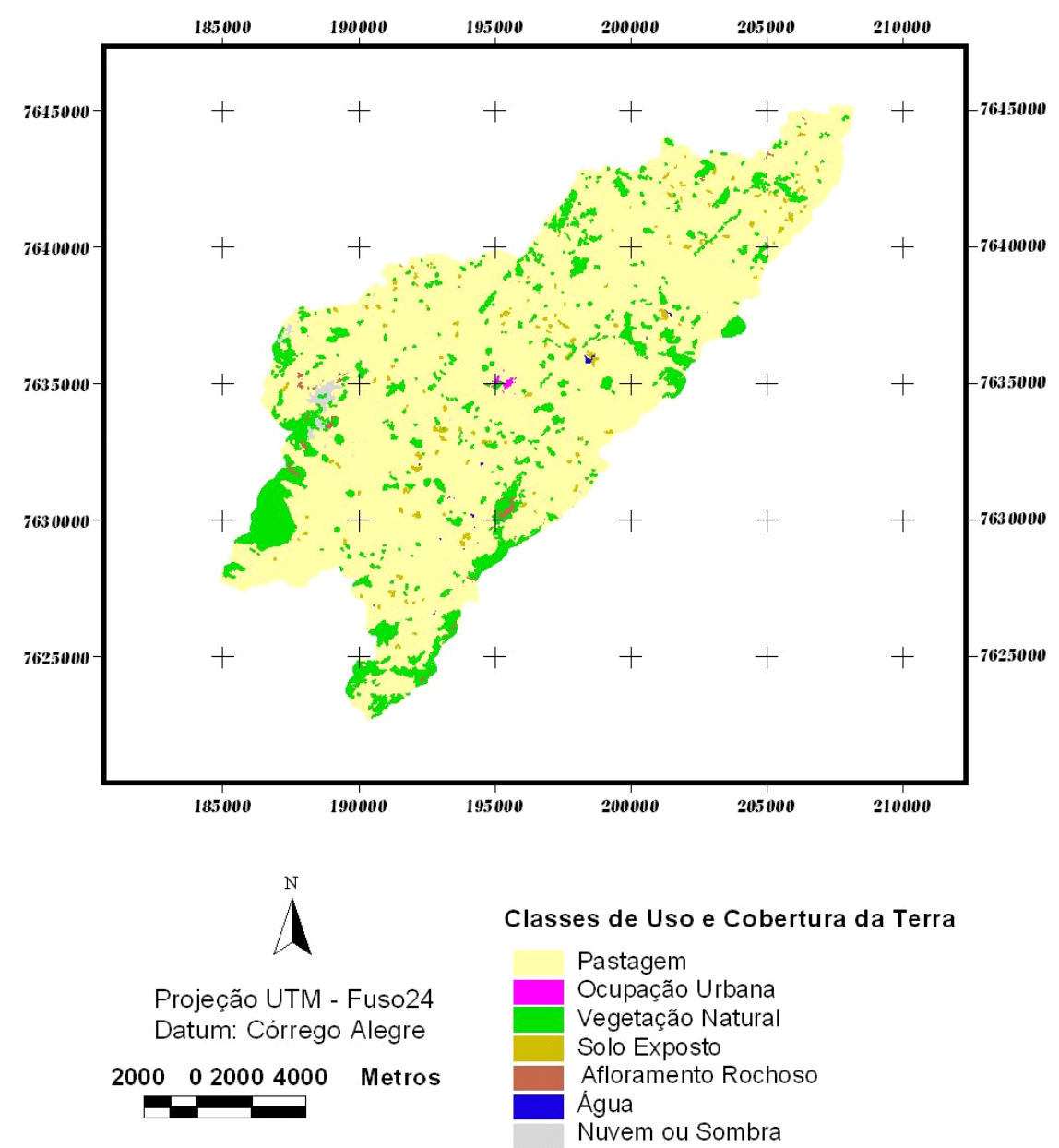

Figura 2. Mapeamento do uso e cobertura da terra da bacia hidrográfica do rio São Domingos.

A classe Pastagem corresponde às áreas cobertas por pastagem sob diferentes manejos, incluindo pasto sujo. É a classe predominante na bacia, ocupando 88,30\% de sua área.

A Ocupação Urbana corresponde à área de maior densidade populacional na bacia hidrográfica, onde se localiza a sede do município de São José de Ubá. Abrange 0,14\% da área da bacia.

A Vegetação Natural é constituída por áreas cobertas por remanescentes da vegetação natural, sendo, em sua maioria, pequenos fragmentos, com exceção de uma área a oeste da bacia, que apresenta a maior área contínua de vegetação natural (480 hectares). Essa classe ocupa 9,24\% da área da bacia.

A classe Solo Exposto compreende as áreas sem cobertura vegetal, incluindo aquelas preparadas para cultivo, ou ainda, áreas erodidas e áreas sob atividade de mineração. Totalizam $0,73 \%$ da área da bacia.

As áreas de Afloramento Rochoso ocorrem na proximidade dos divisores da bacia, em local de relevo montanhoso e de declividade acentuada, abrangendo 0,65\% da área. 
Foram ainda delimitadas as classes: Água, que corresponde aos lagos e represas distribuídos por toda a bacia, abrangendo $0,20 \%$ de sua área; e Nuvem e Sombra, que totalizaram $0,74 \%$ da área da bacia.

No inverno de 2004 foram cultivados 132,27 hectares de tomate, 18,6 ha de pimentão, 9,59 ha de pepino e 1,27 ha de abobrinha. No verão de 2004/2005 foram cultivados 130,07 ha de milho e 66,48 ha de arroz. Essas áreas compõem-se de pequenas parcelas de cultivo e apresentam distribuição não uniforme ao longo da bacia (Figura 3).

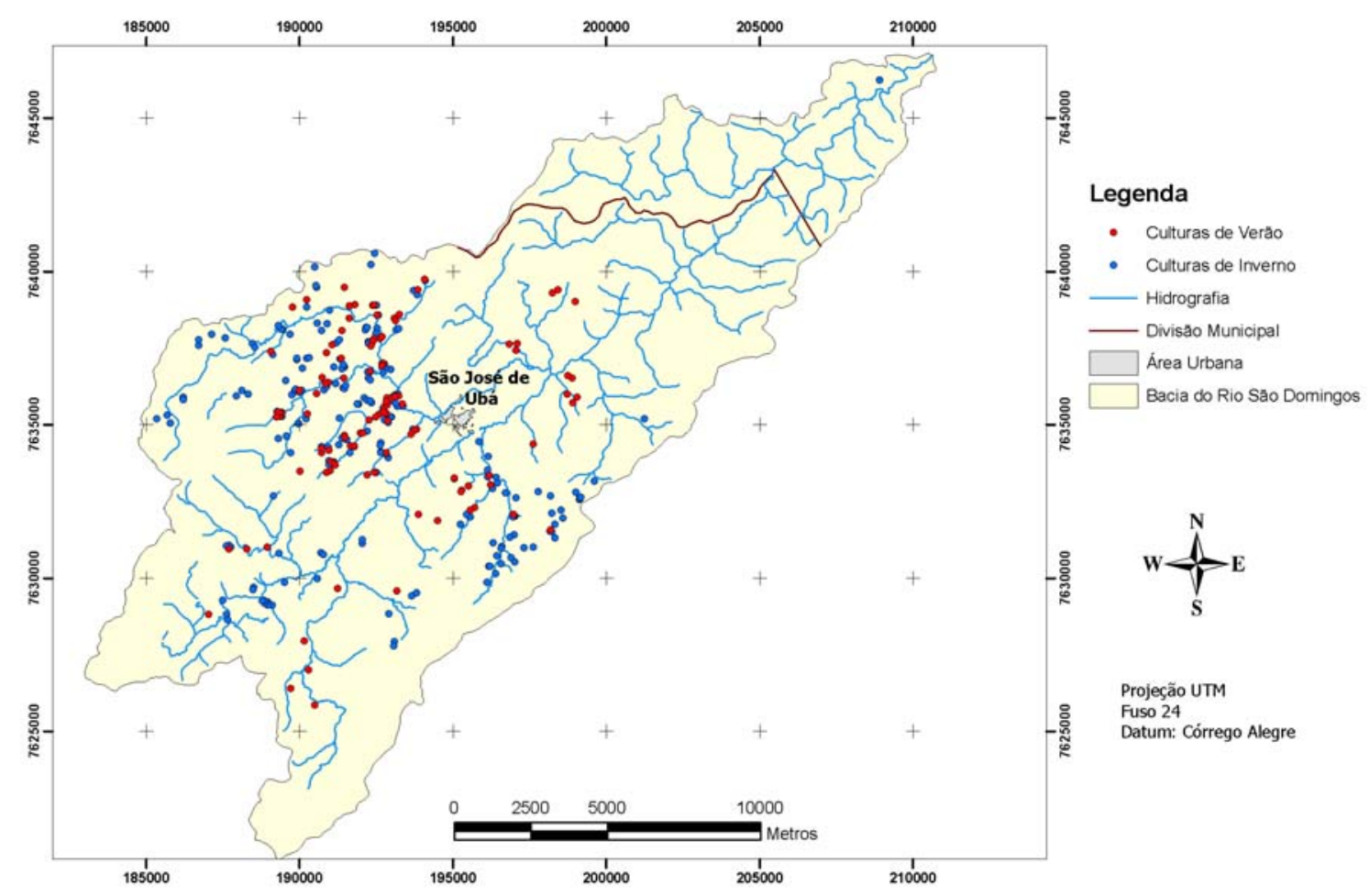

Figura 3. Distribuição das culturas de inverno e verão na bacia hidrográfica do rio São Domingos.

As APPs estão distribuídas por toda a bacia do rio São Domingos (Figura 4) e representam 38\% da área total da bacia. A maior parte das APPs encontra-se ocupada por pastagens. Apenas 17,8\% encontram-se cobertas por vegetação natural. 10\% das lavouras no período de inverno encontravam-se localizadas em APPs. No caso das culturas de verão, $17 \%$ das lavouras encontravam-se em APPs.

A ocupação das áreas de preservação com culturas anuais, favorecem os processos de erosão e assoreamento dos rios da bacia. Observa-se muitos rios assoreados na área da bacia, que atualmente não apresentam fluxo de água durante grande período do ano. Além disso, muitas culturas anuais, especialmente as cultivadas no inverno nesta região, demandam uso intensivo de insumos. Sua proximidade dos cursos d'água aumentam a possibilidade de resíduos atingirem esse recurso. Resultados de estudos da qualidade da água na bacia, desenvolvidos no âmbito do projeto citado indicam a presença de agrotóxicos e a ocorrência de diversos parâmetros em desconformidade com os limites estabelecidos pela legislação (Fernandes et al. 2005; Menezes, 2005; Prado et al., 2005). 


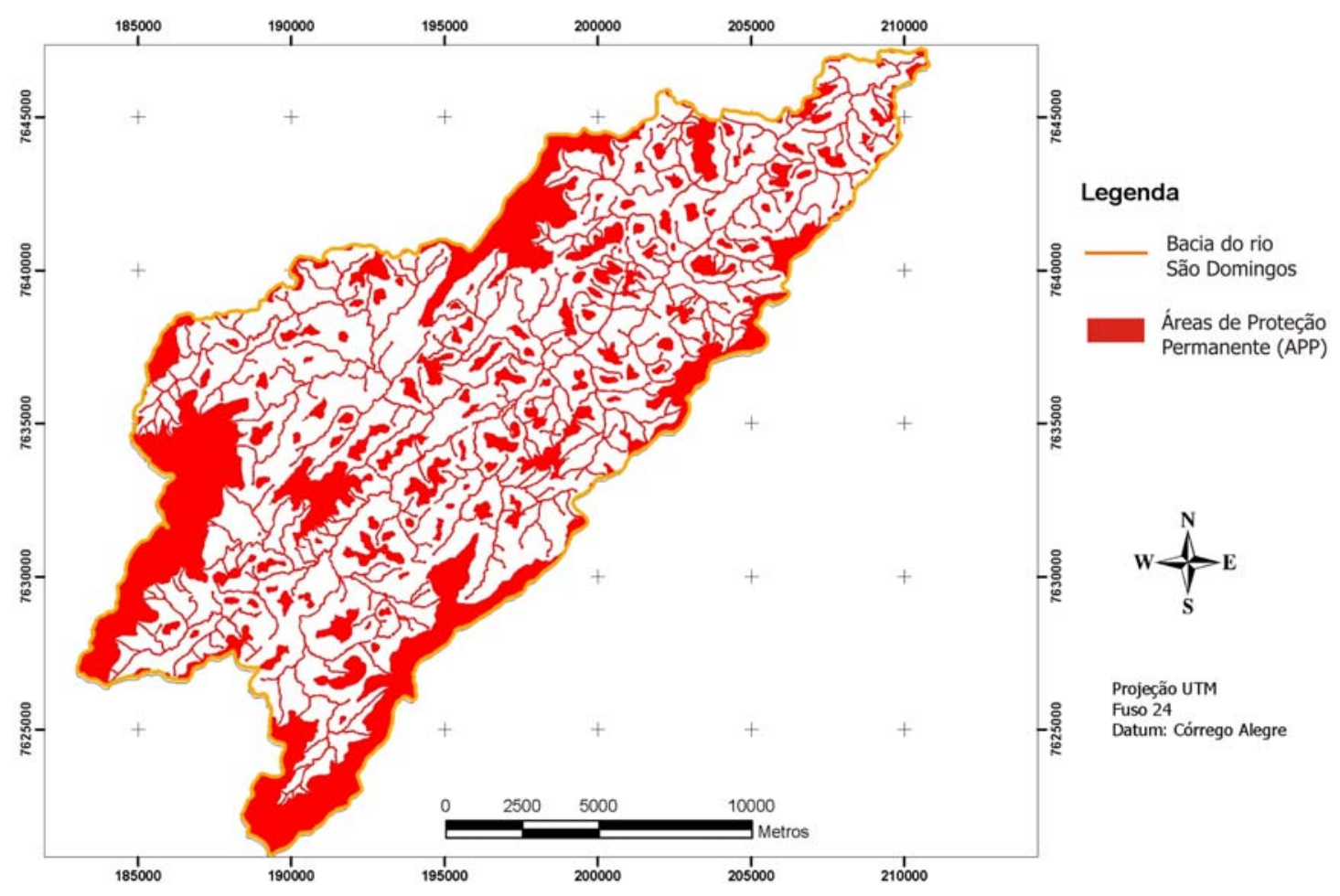

Figura 4. Mapeamento das áreas de preservação permanente na bacia hidrográfica do rio São Domingos.

\section{Conclusão}

O levantamento realizado permitiu identificar que a classe de uso e cobertura da terra predominante na bacia hidrográfica do rio São Domingos é a pastagem, ocupando quase $90 \%$ da área. A falta de proteção de suas áreas de preservação permanente é verificada pela cobertura vegetal reduzida e pela ocupação de algumas dessas áreas por atividades agrícolas intensivas, que envolvem o cultivo de culturas anuais.

\section{Referências}

Brasil. Lei no 4771, de 15 de setembro de 1965. Código Florestal. Diário Oficial da União, Brasil, 16 set. 1965. Disponível em: <http://www.senado.gov.br/legisla.htm>. Acesso em: 02 jun. 2003.

Brasil. Lei $n^{0}$ 7803, de 18 de julho de 1989. Diário Oficial da União, Brasil, 20 jul. 1989. Disponível em: <http://www.senado.gov.br/legisla.htm>. Acesso em: 02 jun. 2003.

CONAMA. Resolução 303, de 20 de março de 2002. Diário Oficial da União, Brasil, 13 mai. 2002. Disponível em: <http://www.mma.gov.br/port/conama/legiano.cfm?codlegitipo=3>. Acesso em: 25 jun. 2006.

Fernandes, D. R.; Menezes, J. M.; Silva, G. C. da; Prado, R. B.; Lucas, S. N. F. P.; Oliveira, E. S. Determinação de Agrotóxicos organoclorados (OCs) e organofosforados (OPs) em águas da bacia hidrográfica do rio São Domingos, RJ. In: Encontro Nacional de Química Analítica/I Congresso Ibero-Americano de Química Analítica, 13., 2005, Rio de Janeiro. Anais... Rio de Janeiro: Universidade Federal Fluminense, 2005. CDROM. 
Fidalgo, E. C. C.; Abreu, M. B. Uso de imagens ASTER para o mapeamento do uso e cobertura da terra na bacia hidrográfica do rio São Domingos, RJ. In: Simpósio Brasileiro de Sensoriamento Remoto (SBSR), 12., 2005, Goiânia. Anais... São José dos Campos: INPE, 2005. Artigos, p. 3747-3753. CD ROM, On-line. ISBN 85-17-00018-8. Disponível em: <http://marte.dpi.inpe.br/col/ltid.inpe.br/sbsr/2005/ 02.12.16.31/doc/@sumario.htm>. Acesso em: 07 ago. 2006.

Gonçalves, A. O.; Fidalgo, E. C. C.; Bastos, C. L. Caracterização climática do município de São José de Ubá, Estado do Rio de Janeiro. Rio de Janeiro: Embrapa Solos, 2006. (Embrapa Solos. Boletim de Pesquisa e Desenvolvimento, n. 95). Disponível em: <http://www.cnps.embrapa.br/solosbr/ publicacao.html>. Acesso em: 30 out. 2009.

Instituto Brasileiro de Geografia e Estatística (IBGE). São João do Paraíso: folha SF-24-G-I-3. Rio de Janeiro, 1968. Escala 1:50.000. Carta topográfica.

Instituto Brasileiro de Geografia e Estatística (IBGE). Miracema: folha SF-23-X-D-III-4. Rio de Janeiro, 1976. Escala 1:50.000. Carta topográfica.

Lima, L. A. de. Vulnerabilidade geral de aquíferos fraturados: bacia hidrográfica do rio São Domingos, São José de Ubá, RJ. 2009. 102p. Dissertação (Mestrado em Geologia) - Universidade Federal do Rio de Janeiro. 2009.

Martorano, L. G.; Rossiello, R. O. P.; Meneguelli, N. A.; Lumbreras, J. F.;Valle, L. S. S.; Motta, P. E. F. da; Rebello, E. R. G.; Said, U. P.; Martins, G.S. Aspectos climáticos do noroeste fluminense, RJ. Rio de Janeiro: Embrapa Solos, 2003. (Embrapa Solos. Documentos, n. 43). Disponível em: $<$ http://www.cnps.embrapa.br/solosbr/ publicacao.html>. Acesso em: 30 out. 2009.

Menezes, J. M. Hidrogeoquímica de aqüíferos fraturados no noroeste fluminense: bacia hidrográfica do rio São Domingos, RJ. 2005. 181 p. Dissertação (Mestrado em Geologia) - Universidade Federal do Rio de Janeiro. 2005.

Prado, R. B.; Menezes, J. M.; Mansur, K. L.; Martins, A. M.; Freitas, P. L. de; Silva Junior, G. C. da; Carvalho, L. G.; Pimenta, T. S. Parâmetros de qualidade da água e sua relação com as fontes de contaminação antrópicas e naturais: bacia hidrográfica do rio São Domingos, São José de Ubá, RJ. In: simpósio Brasileiro de Recursos Hídricos, 16., 2005, João Pessoa. Anais... Porto Alegre: Associação Brasileira de Recursos Hídricos, 2005.

Xavier, M. C. A.; Paiva, C. M.; Alves, G. S.: Classificação e indício de mudança climática em Itaperuna, RJ. In: Congresso Brasileiro de Meteorologia, 11., 2000, Rio de Janeiro. Anais... Rio de Janeiro: Sociedade Brasileira de Meteorologia, 2000. CD-ROM. 